\title{
Gastrointestinal Nematodiasis in Quail in Bangladesh
}

\section{Md. Aminul Islam ${ }^{1 *}$, A.N.M. Aminoor Rahman ${ }^{2}$, Mohammad Shah Alam ${ }^{3}$ and Md. Taimur Islam ${ }^{4}$}

${ }^{1}$ Department of Medicine, Faculty of Veterinary Medicine and Animal Science, Bangabandhu Sheikh Mujibur Rahman Agricultural University, Gazipur 1706, Bangladesh; ${ }^{2}$ Department of Gynecology, Obstetrics and Reproductive Health, Faculty of Veterinary Medicine and Animal Science, Bangabandhu Sheikh Mujibur Rahman Agricultural University, Gazipur 1706, Bangladesh; ${ }^{3}$ Department of Anatomy and Histology, Faculty of Veterinary Medicine and Animal Science, Bangabandhu Sheikh Mujibur Rahman Agricultural University, Gazipur 1706, Bangladesh; ' Department of Pathobiology, Faculty of Veterinary Medicine and Animal Science, Bangabandhu Sheikh Mujibur Rahman Agricultural University, Gazipur 1706, Bangladesh.

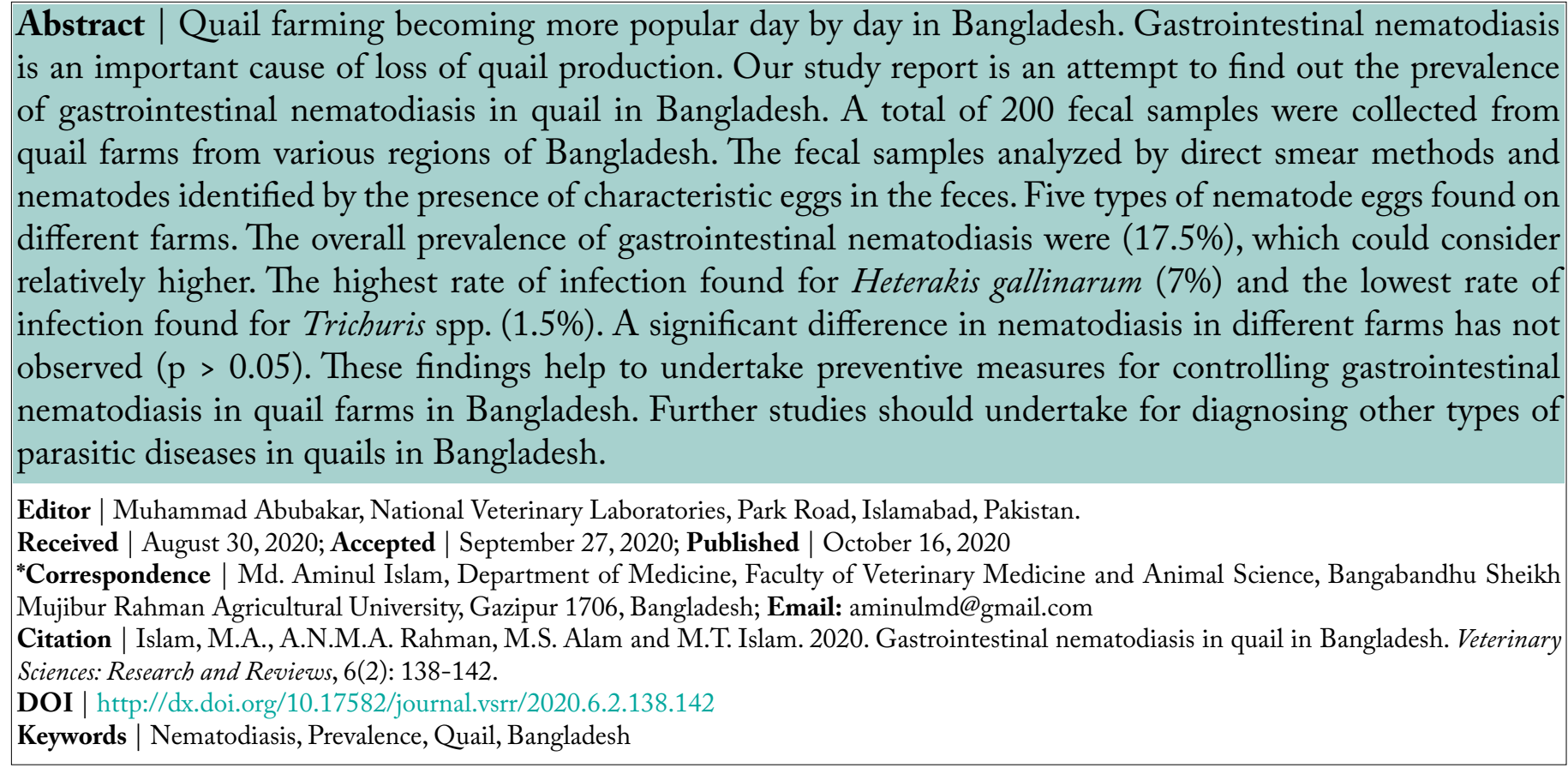

\section{Introduction}

$\mathrm{T}$ he alternative poultry farming, especially Japanese quail (Coturnix coturnix japonica) production already established in Bangladesh, like traditional poultry. This poultry is now quite common in many parts of Bangladesh. As like chicken, Japanese quail in Bangladesh also raised for meat and egg production (Rahman, 2004). The quail eggs are similar in taste to chicken eggs and can use for banquets and other such occasions.

Quail farming is advantageous to chicken farming in several ways (Rahman, 2004). There is minimum requirement of floor space of quails. No need for a big investment. They are comparatively sturdy and strong birds. They can be marketed at five weeks of age (i.e., early age). They become sexually mature early. When the age of quails about 6-7 weeks, they start laying eggs. Like chicken, they produce 280 to 295 eggs/year. The meat of quail is tasty than meat of chicken. Quail meat contain less fat that is crucial for the development of brain and body of the children. The quail eggs are also beneficial for the children; moreover, naturally, because of less fat content. The meat and eggs of quail are also considered nutritious 
for women those are pregnant and/or lactating (Rahman, 2004).

Japanese quails have been in use as laboratory animals in the field of education during the last few decades because of its short generation intervals, high rate of laying, good growth, low feed, small space requirement, and less percentage of mortality. It is also widely used in many areas of behavioral, biomedical (Wilson et al., 1961), and embryological study (Padgett and Ivey, 1960).

Apart from many uses, quails are vulnerable to many helminths and protozoal diseases. These diseases cause diarrhea, lack of appetite, ruffled feathers, uncoordinated movements, impaired intestinal absorption, progressive wasting, weakness, nervous disorder, anemia, reduce weight gain, reduction in growth rate, drop in egg production, high mortality and ultimately substantial economic loss (Rahman et al., 1996). Light infestation leads to subclinical effects such as the reduction in growth rate and ultimately reduces production. Although not studied yet, parasitic diseases may constitute one of the significant constraints for quail farming in Bangladesh. Among the protozoal diseases, coccidiosis causes massive economic loss. Webster, 1982 mentioned, of the other internal parasites, the most common ascarid species to be identified frequently in quails and Psittaciformes was Ascaridia platyceri.

By considering the above facts, the present work has undertaken to obtain complete and detail information on the gastrointestinal helminth infestation in different quail farms in some selected areas of Bangladesh.

\section{Materials and Methods}

\section{Study period and area}

The study was carried out to find out the prevalence of gastrointestinal nematodiasis in quails from July 2012 to June 2013. The fecal samples were collected from quail farms of different regions of Bangladesh, such as Netrokona, Narayanganj, Jashore, and Bogura.

\section{Study questionnaire}

For recording the information of the owner, quail farms, and management practices of quails such as anthelmintic treatment, ration formulation, a study questionnaire developed. The questions were in the English language and translated into the local language during the face to face interview with the owner of the quail farms during the collection of samples. The gathered data organized in Microsoft Excel used for analysis.

\section{Sample collection}

Fecal samples were collected directly from the cloaca of the bird early in the morning. 5-10 grams of fecal material collected for examination. The label depicting particulars of the quail farms, address of the owner, and the date of collection was attached to the wall of the plastic container. The samples immediately transferred to the Medicine laboratory, Faculty of Veterinary Medicine and Animal Science, Bangabandhu Sheikh Mujibur Rahman Agricultural University, Gazipur-1706, Bangladesh. The samples were then examined immediately. If samples not examined immediately, then the samples were kept in the refrigerator $\left(4^{\circ}\right)$ until examination.

\section{Sample examination}

Sample examination was done as previously described by Rahman et al. (1996). A drop of was water placed on the center of a clean glass slide. A small number of feces detached from the given sample with the help of a toothpick and spread out to form a thin smear (thick smears prevent the passing of light through it). Fecal smear was done gently drawing the coarse particles towards a side on the glass slide. A suitable coverslip was put over the smear, and the slide was placed under the low power objective $(10 \mathrm{X})$ of a microscope for examination. For identification of the morphological characteristics of eggs, for each test, at least a two smears prepared from each sample (Hendrix, 2006). The eggs of nematodes diagnosed based on morphological characteristics of eggs of helminths as described by Soulsby (1986).

\section{Statistical analysis}

Statistical analyses were performed using $\mathrm{R}$ software. Means and standard deviations of nematode egg counts calculated, and F-tests used to determine significant differences of nematode eggs among different quail farms. The results considered significant if $p$ values were $\leq 0.05$.

\section{Results and Discussion}

At the present study, a total of 200 samples collected from four different farms of four different regions of 
Bangladesh such as Netrokona (Farm 1), Narayanganj (Farm 2), Jashore (Farm 3), and Bogura (Farm 4). The age of quails of all the farms were $~ 10$ weeks. Out of 200 fecal samples, 35 samples were found positive for different nematodes in different farms.

\section{Farm-wise prevalence}

The farm-wise infection rate shown in Table 1 . The overall farm-wise infection rate of farms $1,2,3$, and 4 are $16 \%, 14 \%, 22 \%$, and $18 \%$, respectively.

Table 1: The farm wise distribution of different nematodes.

\begin{tabular}{|c|c|c|c|c|c|c|}
\hline \multirow{2}{*}{$\begin{array}{l}\text { Farm } \\
\text { number }\end{array}$} & \multirow{2}{*}{$\begin{array}{l}\text { Total } \\
\text { number of } \\
\text { samples }\end{array}$} & \multicolumn{5}{|c|}{ Number of ova } \\
\hline & & $\begin{array}{l}\text { Heterakis } \\
\text { gallinar- } \\
\text { um }\end{array}$ & $\begin{array}{l}A s- \\
\text { carid } \\
\text { spp. }\end{array}$ & $\begin{array}{l}\text { Syngamus } \\
\text { trachea }\end{array}$ & $\begin{array}{l}\text { Tri- } \\
\text { churis } \\
\text { spp. }\end{array}$ & $\begin{array}{l}\text { Cap- } \\
\text { illaria } \\
\text { spp. }\end{array}$ \\
\hline 01 & 50 & 3 & - & 4 & - & 1 \\
\hline 02 & 50 & 6 & - & - & - & 1 \\
\hline 03 & 50 & 2 & 4 & 2 & 1 & 2 \\
\hline 04 & 50 & 3 & - & 4 & 2 & - \\
\hline
\end{tabular}

\section{Prevalence according to species of nematodes}

At the present study, the highest infection rate found for Heterakis gallinarum and the lowest infection rate found for Trichuris spp. The distribution of different nematodes in all the farms have shown in Figure 1. The average nematodiasis of different farms have shown in Figure 2. Amongst the sampled farms, a significant difference in gastrointestinal nematodiasis has not observed $(p>0.05)$ that are shown in Table 2.
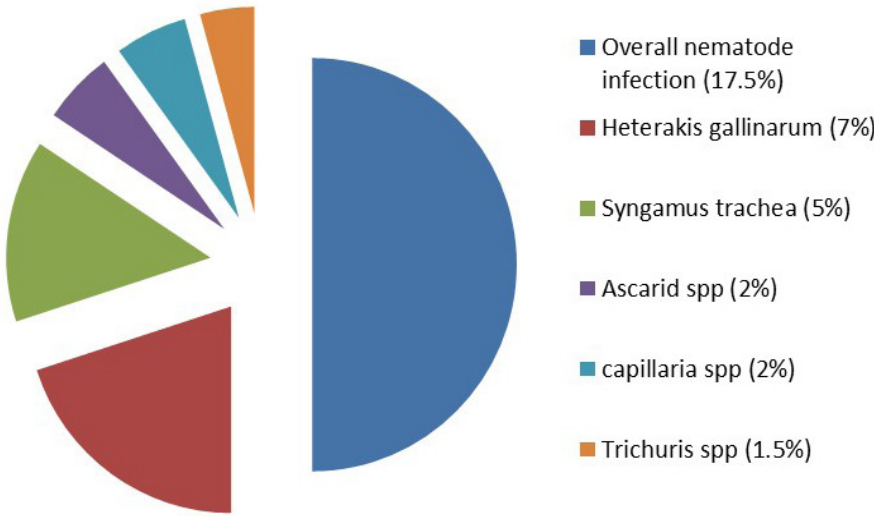

Figure 1: Distribution of different nematodes in all the farms.

There is a growing acceptance of quails in the poultry industry worldwide. Nowadays, quail farming also becoming more popular in Bangladesh. The diversification and faster growth of quail farming in producing eggs and meat simultaneously emphasizes the everyday problems of intensive farming systems.
Parasitic diseases are one of the critical problems of these intensive production systems. The systems of health management and monitoring of intensive quail production is still under the developmental/initial stage in comparing to the poultry sectors. As a result, the products of quail enters in the market of consumer without proper inspection (Barrow and Freitas-Neto, 2011; Parmar and Davies, 2007). To the best of our knowledge, the taxonomy and parasitic biology study in quails have not been conducted in Bangladesh. The aim of the present study was to understand the profile of different parasites of dual-purpose quails (eggs and meats) in the intensive farming systems in different regions of Bangladesh to describe the profile of different parasites of quails.

\section{Table 2: Variations of gastrointestinal nematodiasis among different farms.}

\begin{tabular}{lll} 
Farm number & & p value \\
Farm 1 & Farm 2 & 0.89 \\
Farm 1 & Farm 3 & 0.54 \\
Farm 1 & Farm 4 & 0.87 \\
Farm 2 & Farm 3 & 0.54 \\
Farm 2 & Farm 4 & 0.78 \\
Farm 3 & Farm 4 & 0.68 \\
\hline
\end{tabular}

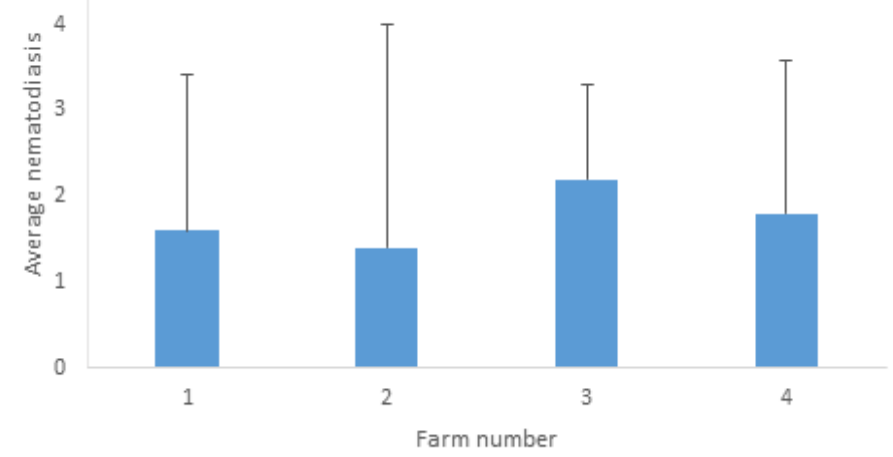

Figure 2: Average nematodiasis in different farms.

At the present study, gastrointestinal nematodiasis diagnosed in all the tested quail farms and a relatively high infection rate $(17.5 \%)$ found in all the farms. All the farms showed mixed infections comprising two or more nematodes (Table 1). Gastrointestinal nematodiasis considered is an essential factor in reducing production from poultry species. The present study elucidates that care should take for the prevention of gastrointestinal nematodiasis in quail farms in Bangladesh. At the present study, during sample collection, all the quail farmers mentioned 
that they used anthelmintics for the control of parasitic diseases to their quail farms, but a record of which anthelmintics used with their doses and frequency of treatment not recorded in the farms. So keeping proper records about using of anthelmintics and other managemental factors suggested for better production from the quail farms. These unrestricted use of anthelmintics may cause serious public health consequences and may also pose for the development of anthelmintic resistant nematodes in quail farms in Bangladesh.

At the present study, the infection rate of nematodes of farms 1,2,3, and 4 were almost similar. A significant difference in nematodiasis among different farms has not observed (Table 2). The probable reason may be the age and sex of the birds was similar in all the quail farms. The birds' age, sex, and management systems have more significant effects on the general health status of birds. Both pathogens and hosts factors influence the intestinal parasitic infestation in birds. The dose size of infective eggs and infective eggs age are crucial parasitic factors. Age, sex, and diet are important host factors. For effective controlling of parasites in quail farms, all the factors mentioned above should consider, and combined management and scheduled medication with effective anthelmintics suggested. However, due to the limitation in the present study, the management system for rearing quails (feed, water, cleaning, and anthelmintic treatment) in different farms has not analyzed because of an improper recording system. Future studies should undertake for finding effects of management on different types of nematodes in the quail population.

At present, as a single nematode, Heterakis gallinarum infection rate was $7 \%$, and this nematode found in all the farms from different regions of Bangladesh that included in the present study. This nematode considered as the most crucial cecal worm of poultry (Permin and Hansen, 1998). They cause severe inflammatory lesions with thickened mucosa of the ceca (typhilitis) with petechiae type hemorrhages. The clinical signs may become unnoticed most of the time, which are even more severe in perspective of quail production. The Heterakis gallinarum also can transmit Histomonas meleagridis, a protozoan causes blackhead disease in fowls. So specific anthelmintic should use for controlling this nematode. At the present study, 8\% Ascarid infection found in Farm 3.
Ascaridia considered as the most important parasite of the small intestine of poultry that might responsible for occlusion of duodenum and/or jejunum (partial or complete). Through ceca, colon, rectum, and cloaca, the mature Ascarid might migrate to the oviduct, and could incorporate with the egg of quail hen's (Permin and Hansen, 1998). The specific clinical signs caused by infection of poultry with Ascarid include inappetance and/or anorexia (partial or complete appetite loss), droopy wings, weight loss, ruffled feathers, reduced production of eggs, anemia, diarrhea and ultimately death (Lima et al., 2014).

At the present study, each of three farms (Farm 1, 3, and 4; Farm 1, 2, and 3) diagnosed with Syngamus trachea and Capillaria spp., respectively. $S$. trachea is the nematode of the trachea or lungs of poultry. $S$. trachea causes difficult respiration. There might be gaping and asphyxia (severe respiratory problem) of the birds if there is accumulation of mucus in the upper respiratory tract. There may be the death of birds when there is blockage of the trachea by mucus. There might be emaciation, anemia, and weakness. Capillaria spp. produces inflammatory lesions as well as thickened crop and esophagus. In heavy infections, there are croupous and catarrhal inflammatory lesions with marked thickened esophagus and crop wall (Permin and Hansen, 1998). At the present study, the lowest infection rate (1.5\%) found for Trichuris spp., which did not mean that the infection of quail with Trichuris spp., can be neglected. Trichuris spp. is also a vital nematode of poultry which causes dysentery, tenesmus, and ultimately growth retardation.

At present, due to limitations, the species of Ascarid spp., Trichuris spp., and Capillaria spp. were not identified. Future studies suggested identifying the species of these nematodes. Because of the present study, only qualitatively methods were used for the diagnosis of eggs of nematodes, future studies should undertake for diagnosing eggs of parasitic diseases of quail by using quantitative methods.

\section{Conclusions and Recommendations}

A relatively higher percentage of gastrointestinal nematodiasis observed in quail farms in different regions of Bangladesh. Future studies should undertake for finding the prevalence of other parasites such as cestodes, trematodes, coccidia, and blood parasites in intensive quail farms in Bangladesh. 
For controlling parasites in quail farms, combined management, and scheduled proper medication with effective anthelmintics suggested. Care should take so that the anthelmintic resistant strain of nematodes not develop. The present research findings help to undertake extensive research on quail parasitic diseases for controlling parasitic quail diseases in intensive quail farms in Bangladesh.

\section{Acknowledgments}

The authors wish to thank Research Management Committee (RMC) Bangabandhu Sheikh Mujibur Rahman Agricultural University, Gazipur-1706, Bangladesh, for providing financial support for the study. The authors also wish to thank all the quail farmers and their employees who contributed to and participated in the study.

\section{Author's Contributions}

Md. Aminul Islam conceptualized the study, responsible for collecting samples, analyze samples, analyze data, writing draft, and final manuscript. ANM Aminoor Rahman helped acquisition of funding. Mohammad Shah Alam and Md. Taimur Islam helped during collection of samples.

\section{Conflict of interest}

The authors have declared no conflict of interest.

\section{References}

Barrow,P.A.and Freitas-Neto,O.,2011.C.pullorum disease and fowl typhoid, new thoughts on old diseases: A review. Avian Pathol., 40(1): 1-13. https://doi.org/10.1080/03079457.2010.5425
75

Hendrix, S., 2006. Laboratory procedures for veterinary technicians, $5^{\text {th }} \mathrm{Ed}$. pp. 812-814.

Lima, H.J.D., Carvalho, L.B., Aquino, M.S., Garrido, L.I., Camargo, M.V.S., Freitas, L.C. and Pacheco, R.C., 2014. Frequência de endoparasitos das famílias Eimeriidae e Ascarididae em codornas japonesas na região metropolitana do Vale do Rio Cuiabá/MT. Zootecnia, 1(1): 7-10.

Padgett, C.S. and Ivey, W.D., 1960. The normal embryology of the Coturnix quail. Anat. Rec., 137: 1. https://doi.org/10.1002/ar.1091370102

Parmar, D. and Davies, R., 2007. Fowl typhoid in a small backyard laying flock. Vet. Rec., 160(10): 348. https://doi.org/10.1136/vr.160.10.348

Permin, A. and Hansen, J.W., 1998. The epidemiology, diagnosis, and control of poultry parasites. FAO, Rome. pp. 25-27.

Rahman, A.N.M.A., 2004. Quail palon (Quail rearing), Bengali edition published: July, 2004/ Aashar 1411; published by Kabir Ahmed, porua, 45, Aziz supermarket (Ground floor), Shahbagh, Dhaka-1000, Bangladesh.

Rahman, M.H., Ahmed, S. and Mondal, M.M.H., 1996. Introduction to helminth parasites of animals and birds in Bangladesh. First edition. pp. 16.

Soulsby, E.J.L., 1986. Helminths, arthropods and protozoa of domesticated animals, $7^{\text {th }}$ Edition, Bailliere Tindall, London.

Webster, W.A., 1982. (Letter) Internal parasites found in exotic birds imported into Canada. Can. Vet. J., 23: 230.

Wilson, W.O., Abbott, U.K. and Abplanalp, H., 1961. Evaluation of Coturnix (Japanese quail) as a pilot animal for poultry. Poult. Sci., 40: 651. https://doi.org/10.3382/ps.0400651 